\title{
A Straddle Monorail Running Gear with Single-Axle and Rotating Arm Axle Box Suspension
}

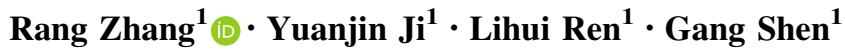

Received: 5 July 2017/Revised: 4 September 2017/Accepted: 11 September 2017/Published online: 10 October 2017

(C) The Author(s) 2017. This article is an open access publication

\begin{abstract}
In this study, a new type of single-axle bogie of straddle-type monorail vehicle is designed. The tumbler structures are adopted in the vertical suspension system. One end of the tumbler is fixed to the framework, while the other end supports the framework via air springs. In addition, the lateral suspension utilizes the suspender way, with longitudinal force transmitted via single pull rods. Guide wheels and steady wheels are connected to the end support arms of the framework through spindles around the horizontal direction. Rubber springs, the pre-compressed magnitudes of which could be adjusted, are set between the spindles and support arms. The multi-body dynamics software UM is adopted to construct a dynamic model and simulate related dynamic performance. The results of the simulation indicate that this new kind of bogie has a favorable performance when passing through curves and has a greater riding stability. The flexibility factor equation of this new monorail vehicle is deduced, with its flexibility factor obtained.
\end{abstract}

Keywords Monorail vehicle $\cdot$ Bogie $\cdot$ Structure . Dynamics

Rang Zhang

1831446545@qq.com

Yuanjin Ji

jiyuanjin@tongji.edu.cn

Lihui Ren

renlihui@tongji.edu.cn

Gang Shen

elsg163@163.com

1 Institute of Rail Transit of Tongji University, No. 4800. Cao an gong Road, Jia ding District, Shanghai, China

Editor: Eryu Zhu

\section{Introduction}

Due to advantages including strong adaptability to complex terrain, low land occupancy, moderate freight volume and low construction cost, straddle-type monorail transportation systems have already become the first choice of urban railway systems in small-medium cities, mountainous cities and cities with topographic and geological complexity [1]. The straddle-type monorail vehicle is mainly supported, guided and stabilized by a single-track beam. The vehicle straddles and runs on the track beam, with the center of gravity of its body located above the track. Comparing to traditional railway vehicles, the running gears of straddle-type monorail vehicles use rubber tires, with guide wheels and steady wheels set on both sides of the track beam. The track beam has a simple structure, playing the roles of bearing structure and track structure. Thus, the performance of the structure can be fully maximized while the maintenance workload of the track beam is of little requirement [2].

Currently, straddle-type monorail vehicles using Hitachi mode and Bombardier mode have both been introduced into China. Hitachi straddle-type monorail vehicles adopt double-axle bogies and thus possess a strong bearing capacity [3], track beam cross section of $850 \times 1500 \mathrm{~mm}$, and power supply of DC1500 V, as shown in Fig. 1. Meanwhile, single-axle bogies are adopted in Bombardier straddle-type monorail vehicles; as shown in Fig. 2, there are four guide wheels and two steady wheels in the bogie, and an hourglass rubber spring are used for secondary suspension paralleling vertical shock absorber and lateral shock absorber. Scomi running gear also uses single-axle structure and rotating arm structure; one end of the rotating arm is hinged with the frame, and the other end is supported by an air spring, and the carbody and bogie are 
Fig. 1 Running gear of a Hitachi straddling monorail vehicle. 1 Framework, 2 walking wheels, 3 guiding wheels, 4 steady wheels, 5 auxiliary wheel, 6 second suspension, 7 and 9 break device, 8 parking break device, 10 driving device, 11 coupling, 12 collector shoe, 13 tire pressure detection device, 14 and 15 sound insulation plate

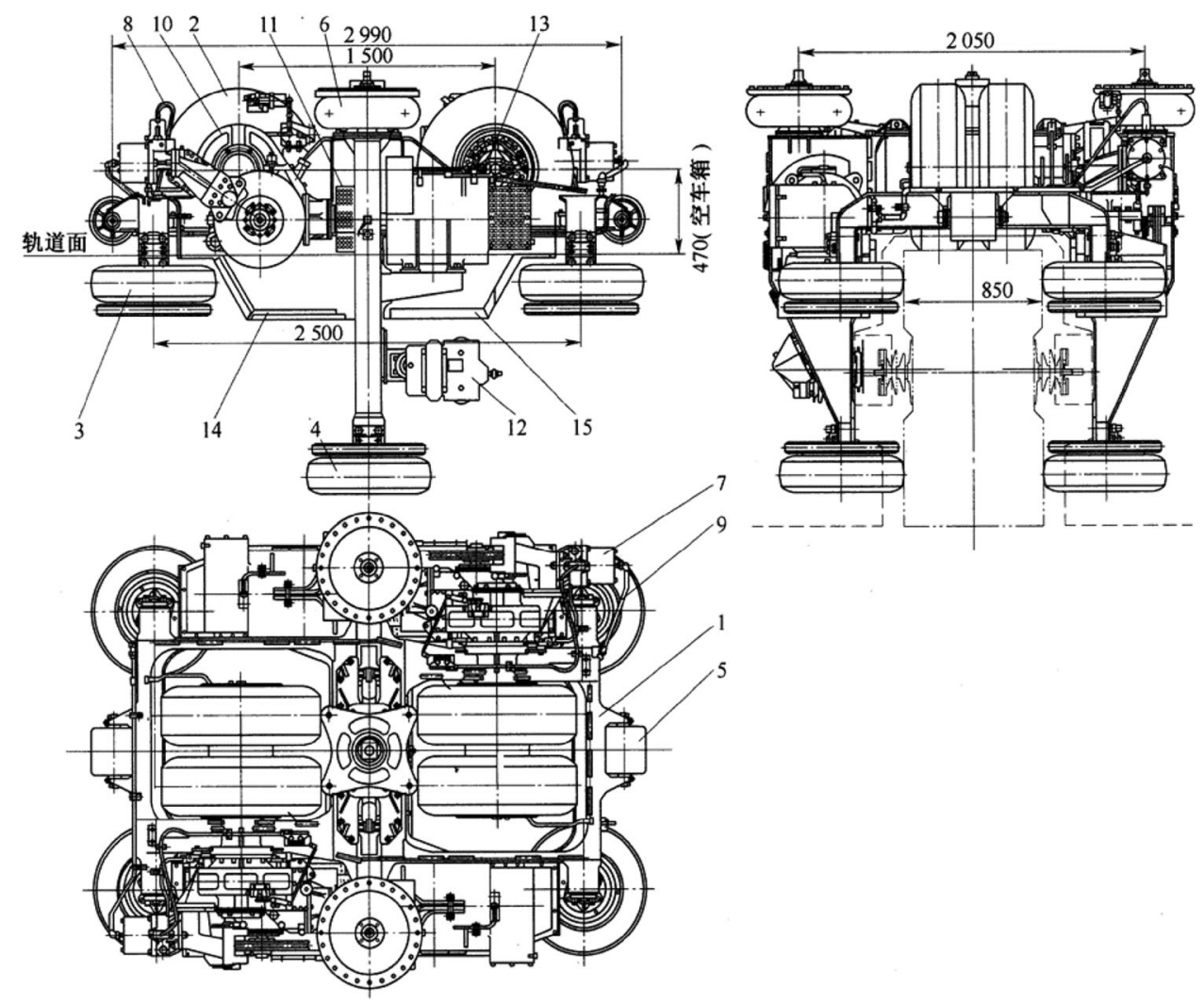

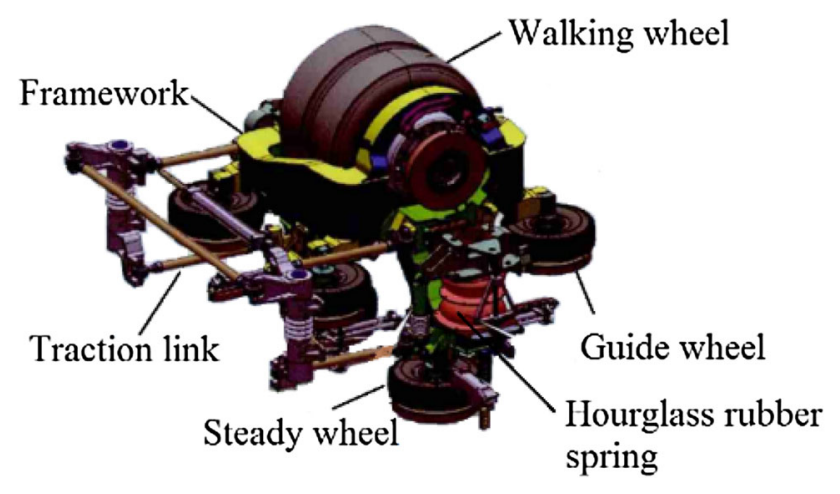

Fig. 2 Running gear of Bombardier

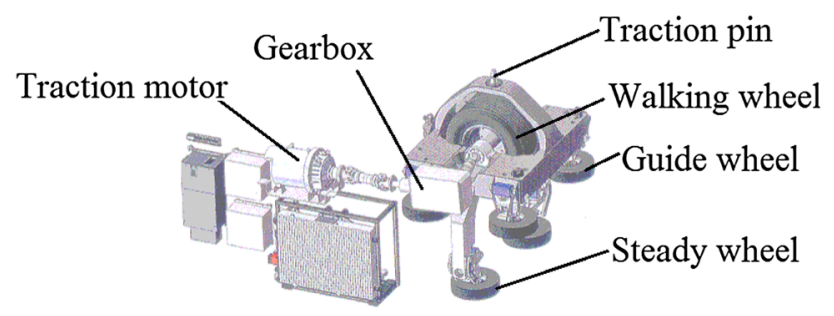

Fig. 3 Running gear of Scomi

connected by a traction pin, as shown in Fig. 3. Comparing to double-axle bogies, single-axle bogies have a stronger curve passing through capacity and can achieve the floor lowering of the passenger rooms. In addition, the vehicles also have a flexible marshaling capacity [4]. Different from wheel-track-type railway vehicles, the product types of the straddle-type monorail vehicles are less numerous, mainly due to the limited types of running parts. Therefore, this study designs a new type of single-axle bogie for straddletype monorail vehicles and analyzes its dynamic performances, and aims to enrich the types of straddle-type monorail vehicles.

\section{Structure of Running Gear}

The bogie of new straddle-type monorail vehicles uses the single-axle structure type and mainly consists of one pair of walking wheels, four guide wheels, one pair of steady wheels, a suspension device and a framework, as shown in Fig. 4.

The walking wheels use the integral wheel pair structure, as well as the installation structure similar to brake discs. The hubs of two rubber pneumatic tires are installed onto the axle via push mounting. The tires rotate together with the axle. Axle boxes are designed outside of the walking wheel axle, to convert the rotation of walking wheel into translation. Tumbler structure is utilized in the axle box body. One end of the tumbler is fixed to the lower part of the framework via rotational joints, while the other end supports the framework via air springs. Holes are open 
Fig. 4 3D schematic diagram of the bogie

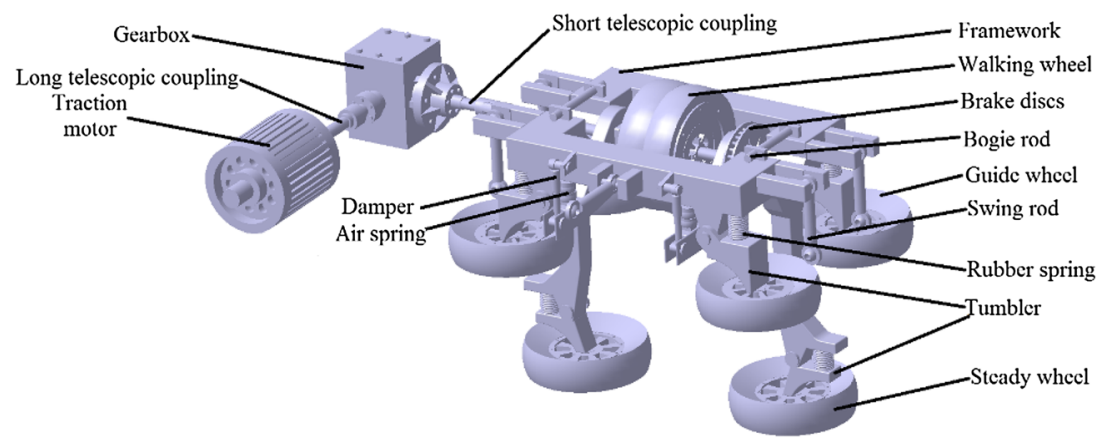

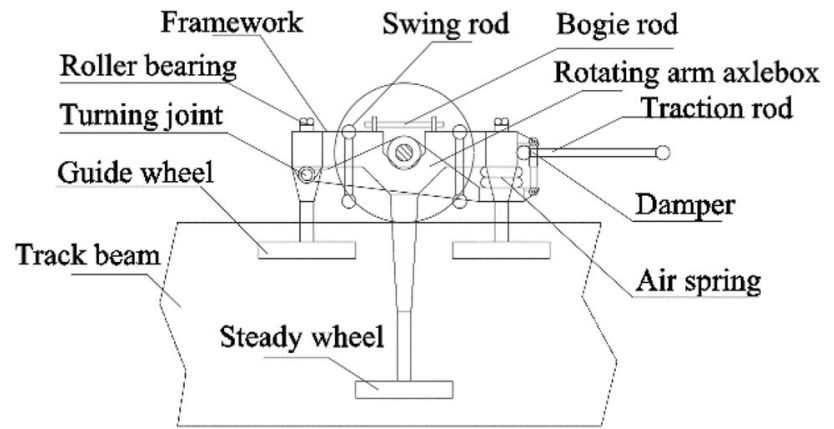

Fig. 5 Schematic diagram of the suspension structure

in the center of tumbler to install the axle box, as shown in Fig. 5. Via the tumbler axle box structure, the longitudinal location and vertical load bearing of walking wheels are achieved. Meanwhile, vertical cushion and vibration attenuation are realized by the air springs and vibration absorbers on one end of the tumbler. Lateral elasticity is realized by suspenders. The suspender top is connected to the framework, while its bottom is connected to the carbody. Through the lateral oscillation of suspenders, the lateral cushion is realized depending on the carbody gravity. At the same time, the deflection between the carbody and bogie during nonlinear motion when passing through curves can be adapted via the vertical oscillation of the suspenders. A single traction rod is assigned to the crossbeam in order to transmit the longitudinal tractive force and braking force.

Guide wheels and steady wheels are connected to the end support arms of the framework through spindles around the horizontal direction. Rubber springs are set between the spindles of the guide wheels, steady wheels and support arms. By adjusting the pre-compression amount of the springs, the pre-pressure between the guide wheels or steady wheels and the track beam can then be adjusted.

The main body of the framework presents a rectangular shape, mainly consisting of two side beams and two crossbeams. The support beams of the steady wheels are set below the center of the side beam in the framework, and the support beams of the guide wheels are set below the

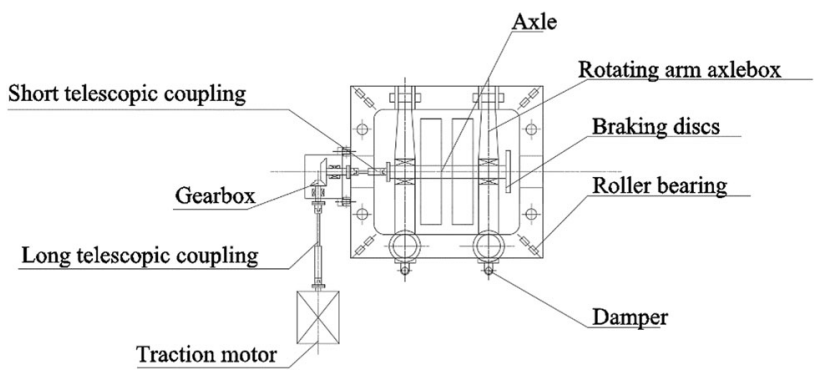

Fig. 6 Schematic diagram of the traction system

ends of the side beams. The center of the side beam in the framework concaves downward, to allow couplings to pass through. On both sides of the concaved part of the side beam within the framework, pull rod bases are set to install pull rods, aiming to improve the loading condition of the framework, as well as increase its strength.

The traction motor is installed on the under-frame of the carbody and is connected to the input shaft of the gearbox via a retractable universal spindle coupling. The gearbox is fixed to the side beam in the framework. Transmission gear groups are installed inside the gearbox. Bevel gears are used in the transmission gear groups, with small gears installed on the input shaft while large gears are installed on the output shaft. The output shaft of the gearbox is connected to the axle via another shaft coupling. The walking wheel is fixed on the axle via a hub and rotates together with the axle, as shown in Fig. 6. Thus, the bogie mass is reduced, and the bogie structure is simplified.

\section{Analysis of Dynamic Performance}

\subsection{Dynamic Model}

To verify the dynamic performance of the new monorail vehicle bogie, the UM software with multi-body dynamics is used to analyze the dynamic vehicle model. The dynamic model mainly consists of one carbody, two frameworks, four walking wheels, eight guide wheels and four steady wheels. The carbody and bogie frameworks are both treated as rigid bodies. Suspension devices, including air 
Fig. 7 Topological structure of the vehicle dynamic model

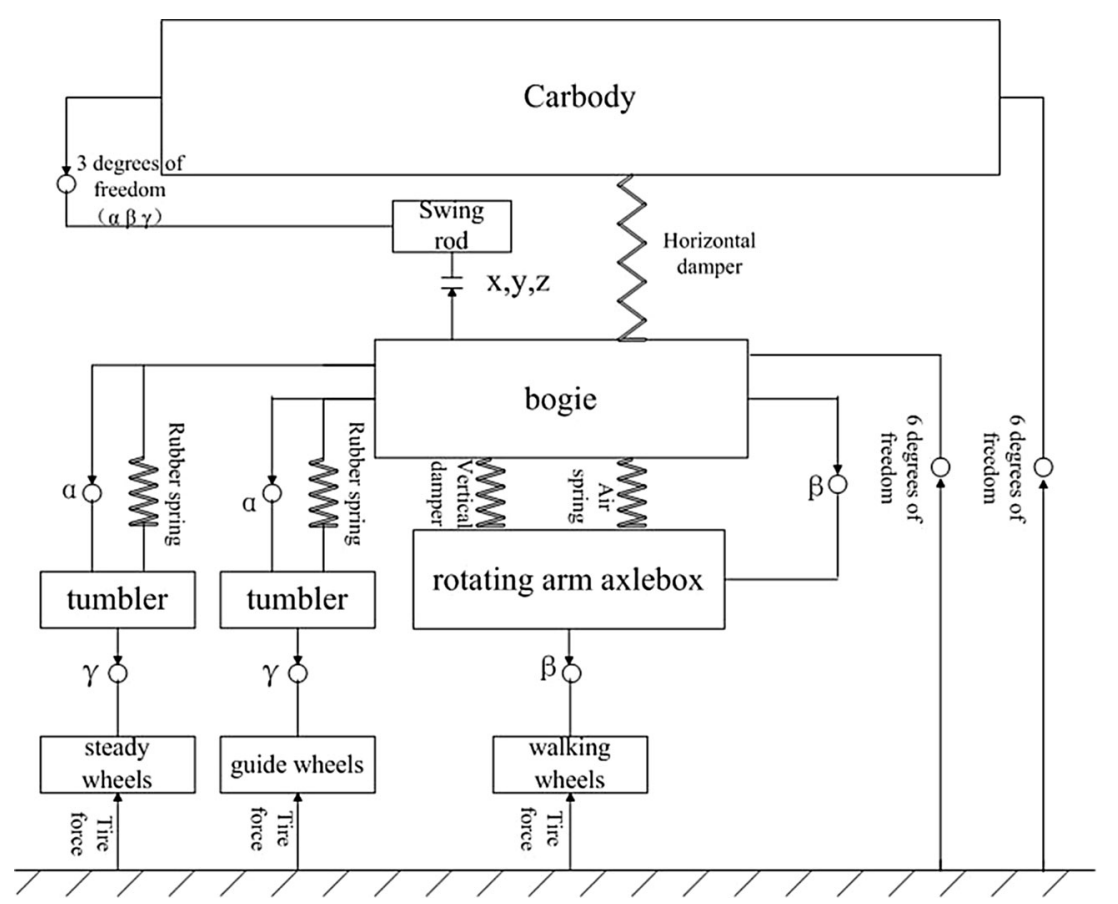

springs, suspenders, absorbers, are all simplified as springdamper force units. Each bogie has four suspenders, distributed on both sides. Tires are modeled based on the Falia model, by taking the radial characteristics and cornering features of the tires into consideration. The walking wheel pairs are connected to the framework via hinge joints rotating around the y-direction. Guide wheels and steady wheels are connected to the corresponding tumblers via hinge joints rotating around the z-direction. The tumblers of the guide wheels and steady wheels are all connected to the framework via hinge joints rotating around the x-direction. The dynamic topological structure of the new monorail vehicle is shown in Fig. 7, with the vehicle dynamic model displayed in Fig. 8. Table 1 gives the main dynamic parameters of the vehicle.

\subsection{Curve Passing-Through Performance}

One of the advantages of the straddle-type monorail vehicles is their strong capacity of maneuvering around small corners. When a vehicle runs through a curve with a small radius, the orbital superelevation and running speed both have significant influences on its passing-through performance $[5,6]$. Figure 9 shows the maximum value of carbody rolling angle, the maximum value of guide wheel radial force and the maximum value of steady wheel radial force, when the vehicle passes through curves with different radii. The superelevation is a total of $6 \%$, and the vehicle speed is kept constant. In a curve with a radius of $60 \mathrm{~m}$, the rolling angle of the carbody is at its greatest, reaching $0.012 \mathrm{rad}$. The rolling angle decreases as the

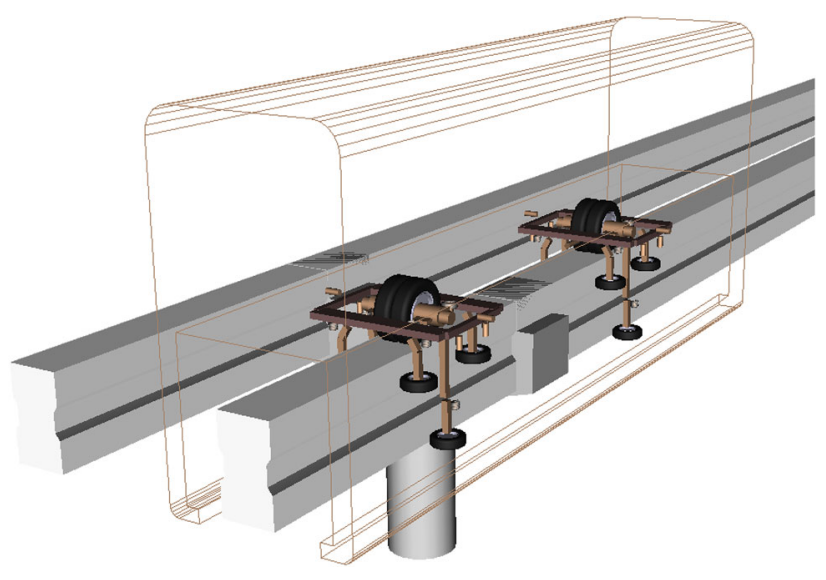

Fig. 8 UM simulation model of vehicle dynamics

curve radius increases. With the increase in the curve radius, the radial force of the guide wheels and steady wheels all reduces and the lateral force of the walking wheels also decreases.

Figure 10 shows the load variation regularity of the wheels in the front and back bogies, during the motion of the vehicle passing through a curve with a radius of $100 \mathrm{~m}$. As shown in the figure, the left rear guide wheel of the front bogie, the right front guide wheel of the front bogie, the left rear guide wheel of the back bogie and the left front guide wheel of the back bogie all experience load increase. The right steady wheel of the front bogie and the left steady wheel of the back bogie both experience load increase. 
Table 1 Vehicle dynamics parameters

\begin{tabular}{ll}
\hline Parameters & Values \\
\hline Carbody mass & $10,000 \mathrm{~kg}$ \\
Bogie mass & $2100 \mathrm{~kg}$ \\
Radial stiffness of walking wheel & $1.4 \mathrm{MN} \mathrm{m}$ \\
Cornering stiffness of walking wheel & $0.35 \mathrm{MN} \mathrm{m} / \mathrm{rad}$ \\
Radial stiffness of guide wheel & $0.65 \mathrm{MN} \mathrm{m}$ \\
Radial stiffness of steady wheel & $0.65 \mathrm{MN} \mathrm{m}$ \\
Stiffness of pre-compressed spring & $12.5 \mathrm{MN} \mathrm{m}$ \\
Vertical stiffness of air spring & $0.15 \mathrm{MN} \mathrm{m}$ \\
Suspender length & $0.65 \mathrm{~m}$ \\
Damping coefficient of vertical absorber & $50 \mathrm{kN} /(\mathrm{m} / \mathrm{s})$ \\
Damping coefficient of lateral absorber & $50 \mathrm{kN} /(\mathrm{m} / \mathrm{s})$ \\
Length between vehicle centers & $6.0 \mathrm{~m}$ \\
Distance between carbody gravity center and rail level & $0.3 \mathrm{~m}$ \\
Distance between bogie gravity center and rail level & $0.2 \mathrm{~m}$ \\
Distance between guide wheel center and rail level & $0.15 \mathrm{~m}$ \\
Distance between steady wheel center and rail level & $0.9 \mathrm{~m}$ \\
Half value of walking wheel transverse distance & $0.15 \mathrm{~m}$ \\
Walking wheel radius & $0.5 \mathrm{~m}$ \\
Guide wheel radius & $0.27 \mathrm{~m}$ \\
Steady wheel radius & $0.27 \mathrm{~m}$ \\
Pre-compression pressure of guide wheel and steady wheel & $5000 \mathrm{~N}$ \\
\hline
\end{tabular}

\subsection{Riding Stability}

In this study, the Sperling index is used to evaluate the riding stability of monorail vehicles. Due to the lack of the track irregularity spectrum of the straddle-type monorail, the ISO8608 A-level road spectrum is used to simulate the track irregularity. After obtaining the acceleration of the vehicle during rectilinear motion, the Sperling index can be obtained based on treatment according to GB5599-85.

Figure 11 shows the lateral and vertical Sperling index values of the vehicle under different speed stage and under the excitation of the ISO8608 A-level road spectrum (the excitation spectrum coefficient is set as 0.5 and 1 , respectively). As shown in Fig. 8, as the speed increases, the riding stability of the vehicle gradually decreases. When the track spectrum coefficient is set as 0.5 , the lateral and vertical stability indexes of the vehicle within the speed range of $90 \mathrm{~km} / \mathrm{h}$ are both lower than 2.5 , corresponding to an excellent level of stability. When the track spectrum coefficient is set as 1 , the speed is lower than $60 \mathrm{~km} / \mathrm{h}$, and the lateral and vertical stability indexes are lower than 2.5, corresponding to the excellent stability level. When the speed ranges between 70 and $90 \mathrm{~km} / \mathrm{h}$, the lateral and vertical stability levels are fine.

\section{Flexibility Coefficient}

The lateral span of the walking wheels in straddle-type monorail vehicles is very short. Hence, steady wheels must be set to improve the capsizing resistance of straddle-type monorail vehicles. The vehicle capsizing resistance is usually evaluated based on the buoyant center height and flexibility coefficient. In the UIC505-5 regulation, the flexibility coefficient is defined as follows: When a vehicle stays on a line with a superelevation of $\delta$, by assuming that the angle between the cross-section centerline of the vehicle and centerline and the line crosssection centerline perpendicular to the track top plane is $\phi$ , the ratio of $\phi$ to $\delta$ is the flexibility coefficient $S$.

According to the definition of the flexibility coefficient, the calculation formula for the flexibility coefficient of this monorail vehicle can be deduced. Figure 8 shows the loading model of the monorail vehicle rolling under lateral force. The carbody and bogies are connected via suspenders. Hence, the carbody and bogies can be considered as a whole. The coordinate system YOZ, consisted by the track beam centerline and the horizontal line of track beam upper surface, is selected as the reference coordinate system. The degrees of freedom of the loading model contain overall lateral moving amount $y$ and overall rolling angle $\phi$. By converting the vertical 


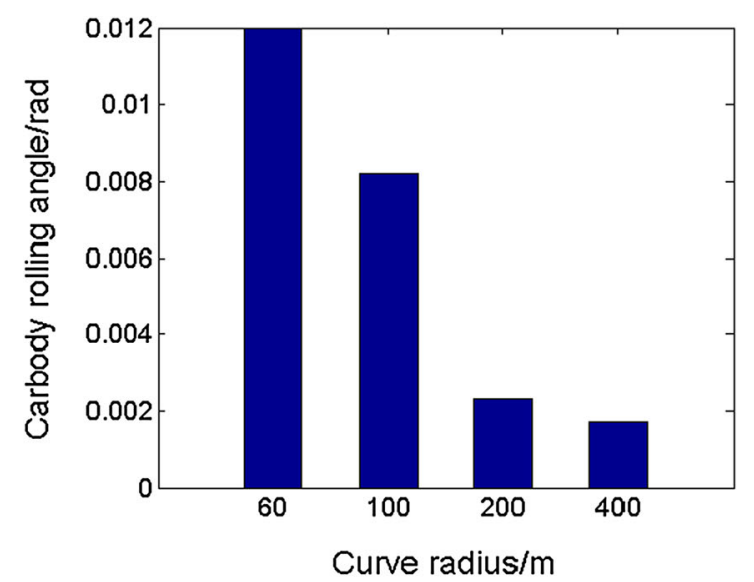

(a)

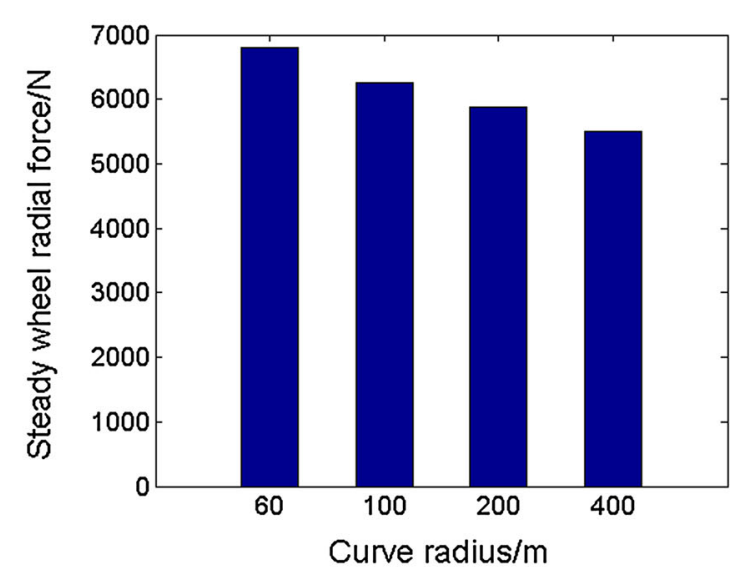

(c)

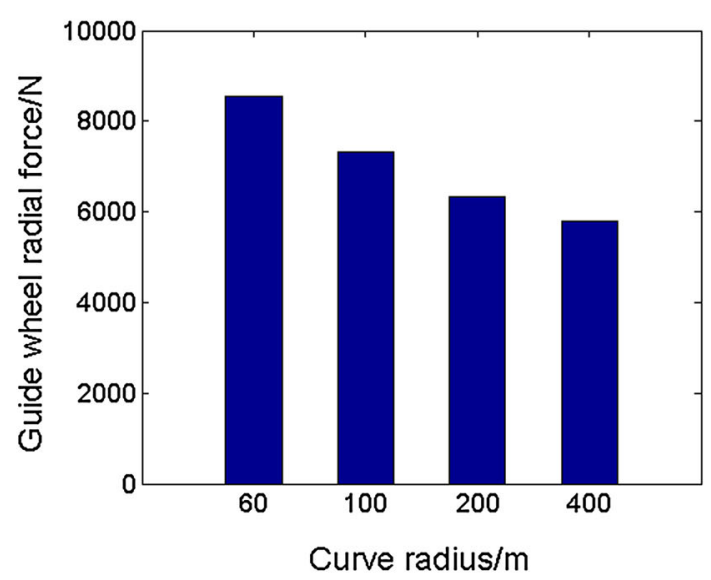

(b)

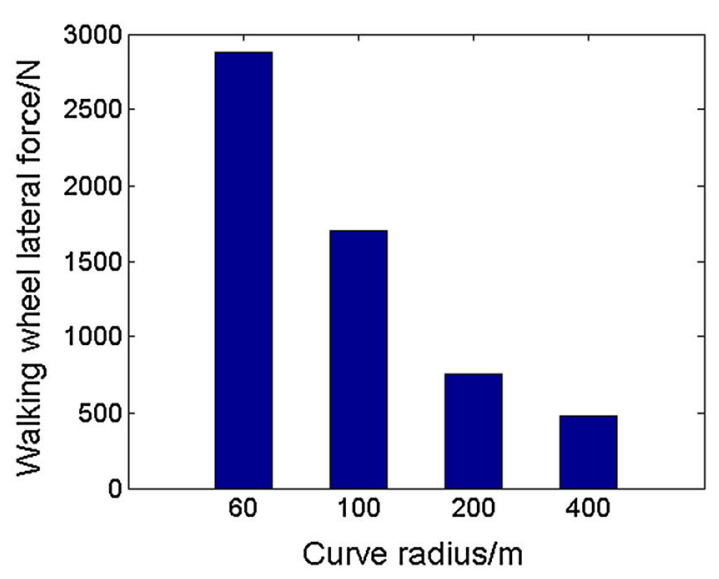

(d)

Fig. 9 Calculation results of curves with different radii, a carbody rolling angle, $\mathbf{b}$ guide wheel radial force, $\mathbf{c}$ steady wheel radial force, d walking wheel lateral force

stiffness of air springs on the tumbler axle box into the stiffness of walking wheel, the equivalent primary suspension stiffness $K_{1 z}$ can be obtained. By converting the vertical stiffness of spring on the tumbler of guide wheels into the radial stiffness of guide wheel, the equivalent radial stiffness of guide wheel $K_{g}$ can be obtained. The equivalent radial stiffness of steady wheels $K_{\text {st }}$ can also be obtained by converting the vertical stiffness of spring on the tumbler of steady wheels into the radial stiffness of steady wheel (Fig. 12).

According to the force analysis model in Fig. 8, the statics equilibrium equation during monorail vehicle rolling can be listed as follows:

1. Overall lateral movement equation

$$
2 K_{g}\left(y-h_{3} \phi\right)-2\left(y-h_{4} \phi\right) K_{\text {st }}+\left(G_{1}+G_{2}\right) \delta=0
$$

2. Overall side rolling equation

$$
\begin{aligned}
- & 2 K_{g}\left(y-h_{4} \phi\right) h_{3}-2\left(y-h_{4} \phi\right) K_{\mathrm{st}} h_{4}-2 K_{1 z} \phi b^{2} \\
& -G_{1}\left[\left(h_{1}+h_{2}\right) \delta+y\right]+G_{2}\left(h_{2} \delta+y\right) \\
& =0
\end{aligned}
$$

By combining the above two equations, the flexibility coefficient equation of this monorail vehicle can be obtained as:

$S=\frac{\phi}{\delta}=\frac{A_{1}-A_{2}}{B_{1}-B_{2}}$

where $A_{1}=\left[2\left(K_{g} h_{3}+K_{\text {st }} h_{4}\right)+G_{1}+G_{2}\right]$

$A_{2}=\left[2 G_{1}\left(h_{1}+h_{2}\right)-G_{2} h_{2}\right]\left(K_{g}+K_{\mathrm{st}}\right)$

$B_{1}=2\left[G_{1}+G_{2}-2\left(K_{g} h_{3}-K_{\text {st }} h_{4}\right)\right]\left(K_{g} h_{3}+K_{\text {st }} h_{4}\right)$

$B_{2}=4\left[G_{1}+G_{2}-\left(K_{g} h_{3}^{2}-K_{\mathrm{st}} h_{4}^{2}-K_{1 z} b^{2}\right)\right]\left(K_{g} h_{3}+K_{\mathrm{st}} h_{4}\right)$ 


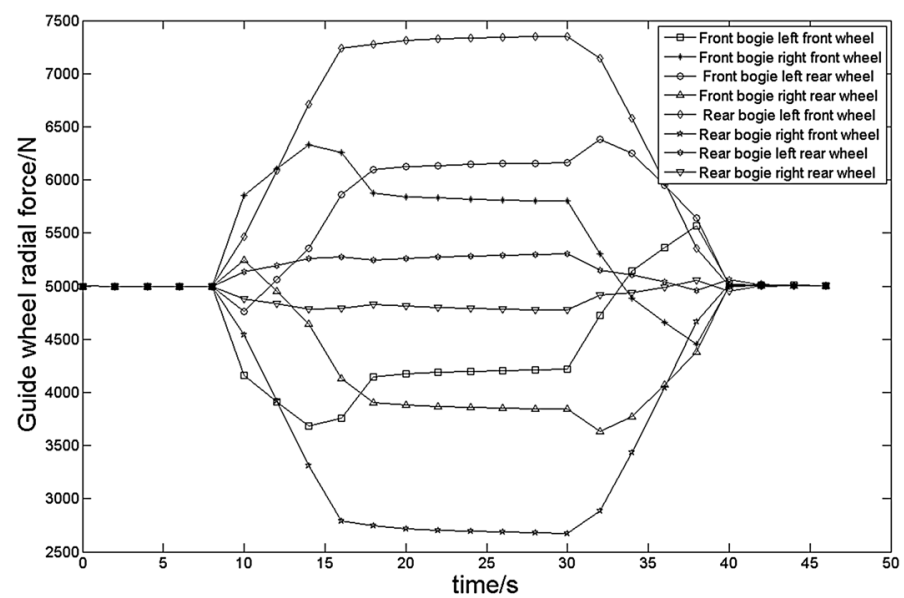

(a)

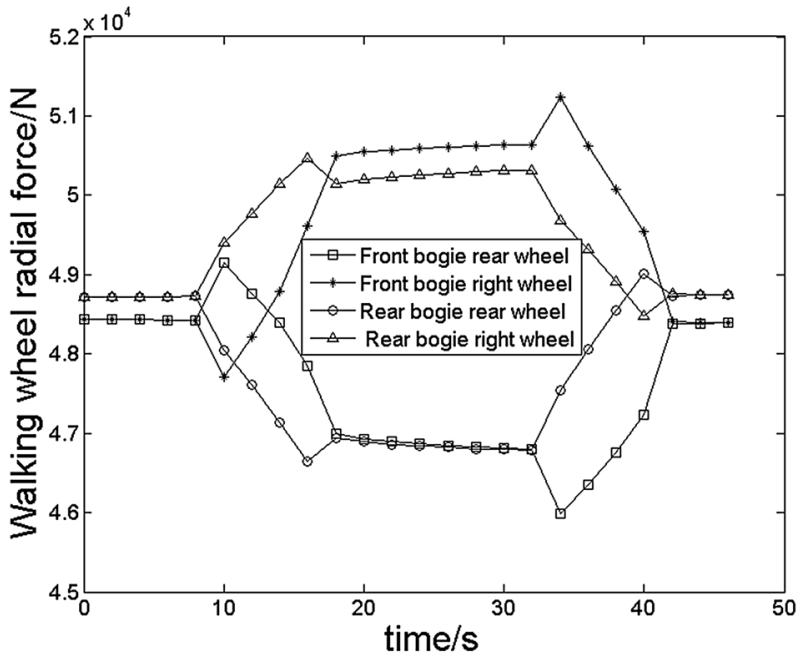

(c)

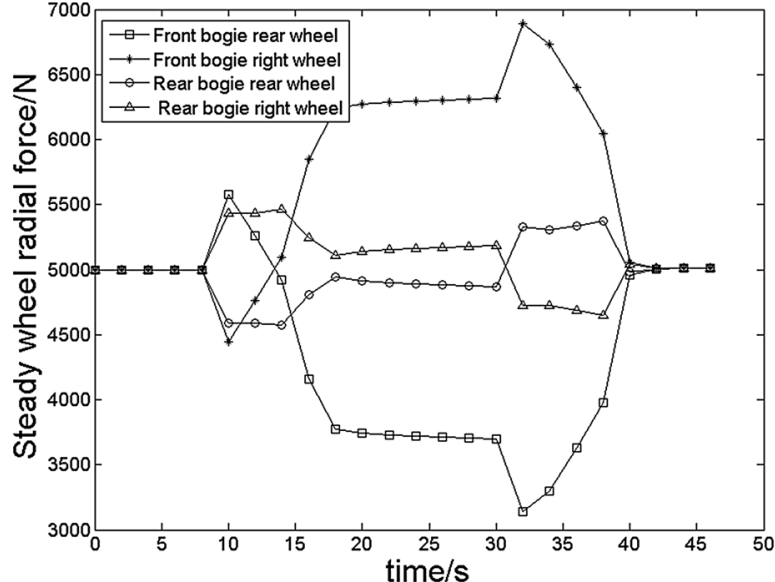

(b)

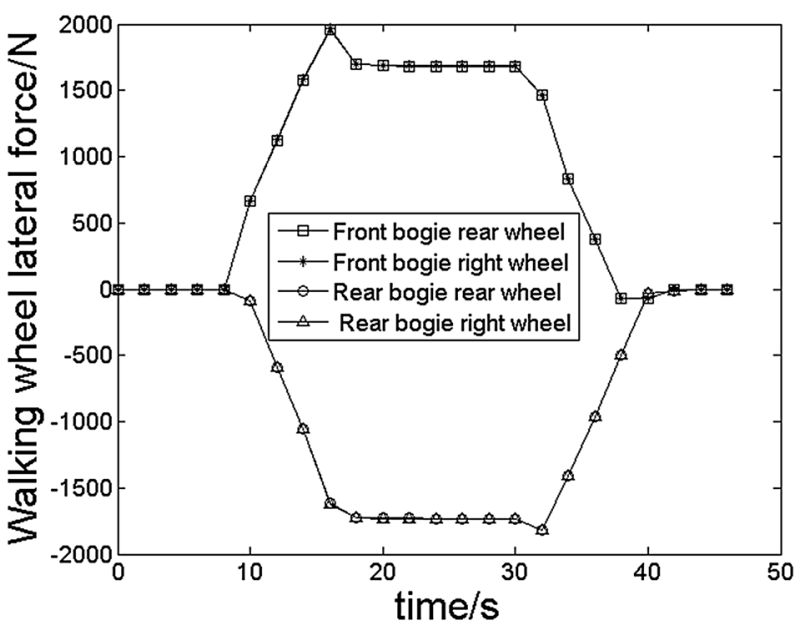

(d)

Fig. 10 Load variation regularity of each wheel in the bogie, a guide wheel radial force, $\mathbf{b}$ steady wheel radial force, $\mathbf{c}$ walking wheel radial force, $\mathbf{d}$ walking wheel cornering force

According to parameters listed in Table 1, the flexibility coefficient of this new straddle-type monorail vehicle can be calculated based on Eq. 3. When all the guide wheels are in contact with the steady wheels at the same time, the flexibility coefficient is 0.284. When steady wheels on one side and guide wheels on the opposite side leave the track surface, the flexibility coefficient is 0.651 . According to the definition of the flexibility coefficient, the greater the flexibility coefficient, the easier it is for the vehicle to capsize on the curves. Hence, to ensure a favorable anti-overturning capacity of the straddling monorail vehicles, a certain degree of preload pressure should be applied on the guiding or stabilizing wheels to guarantee a consistent contact between the wheels and track beam. [7] 


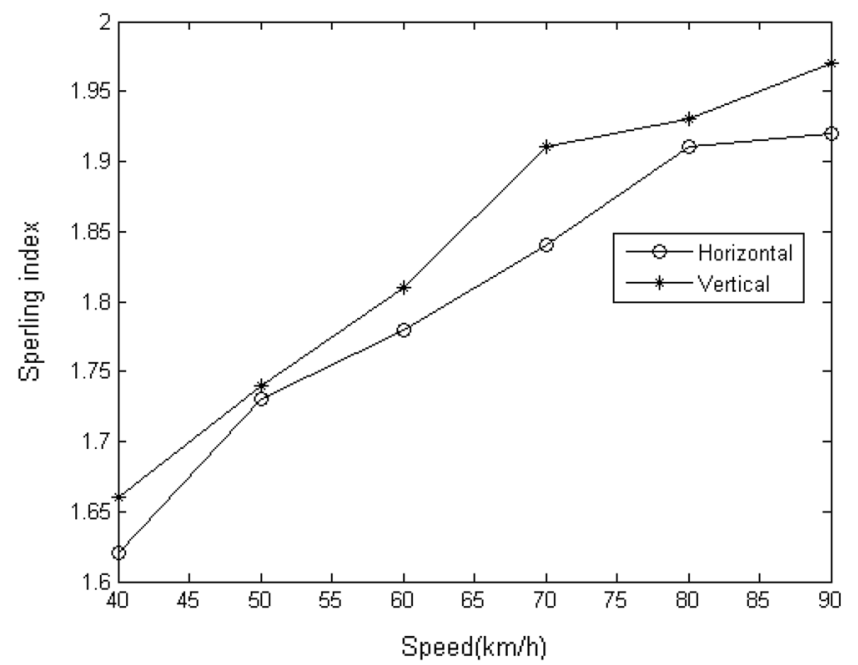

(a)

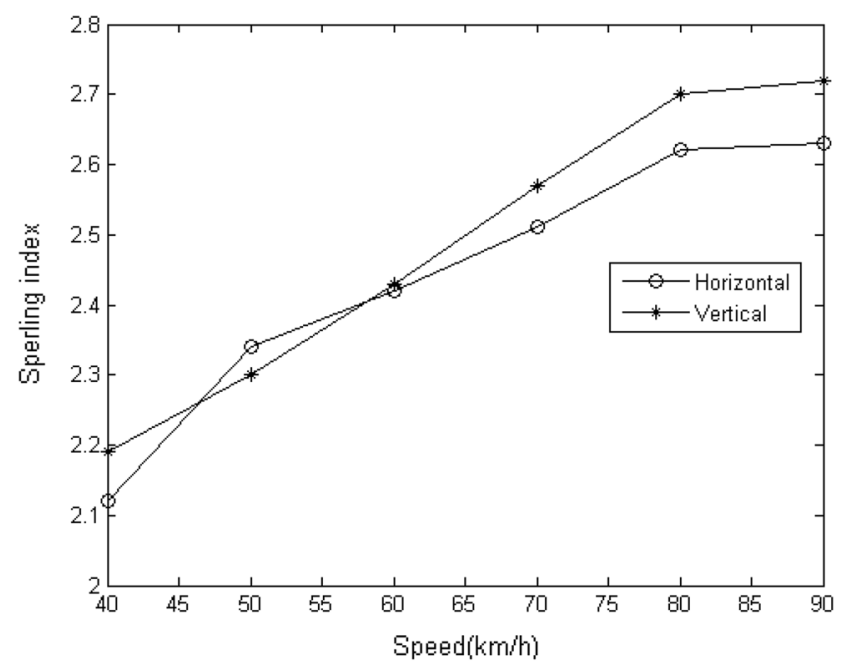

(b)

Fig. 11 Sperling indexes of vehicle, a track spectrum coefficient of 0.5 , b track spectrum coefficient of 1

Fig. 12 Force analysis model of the vehicle during rolling

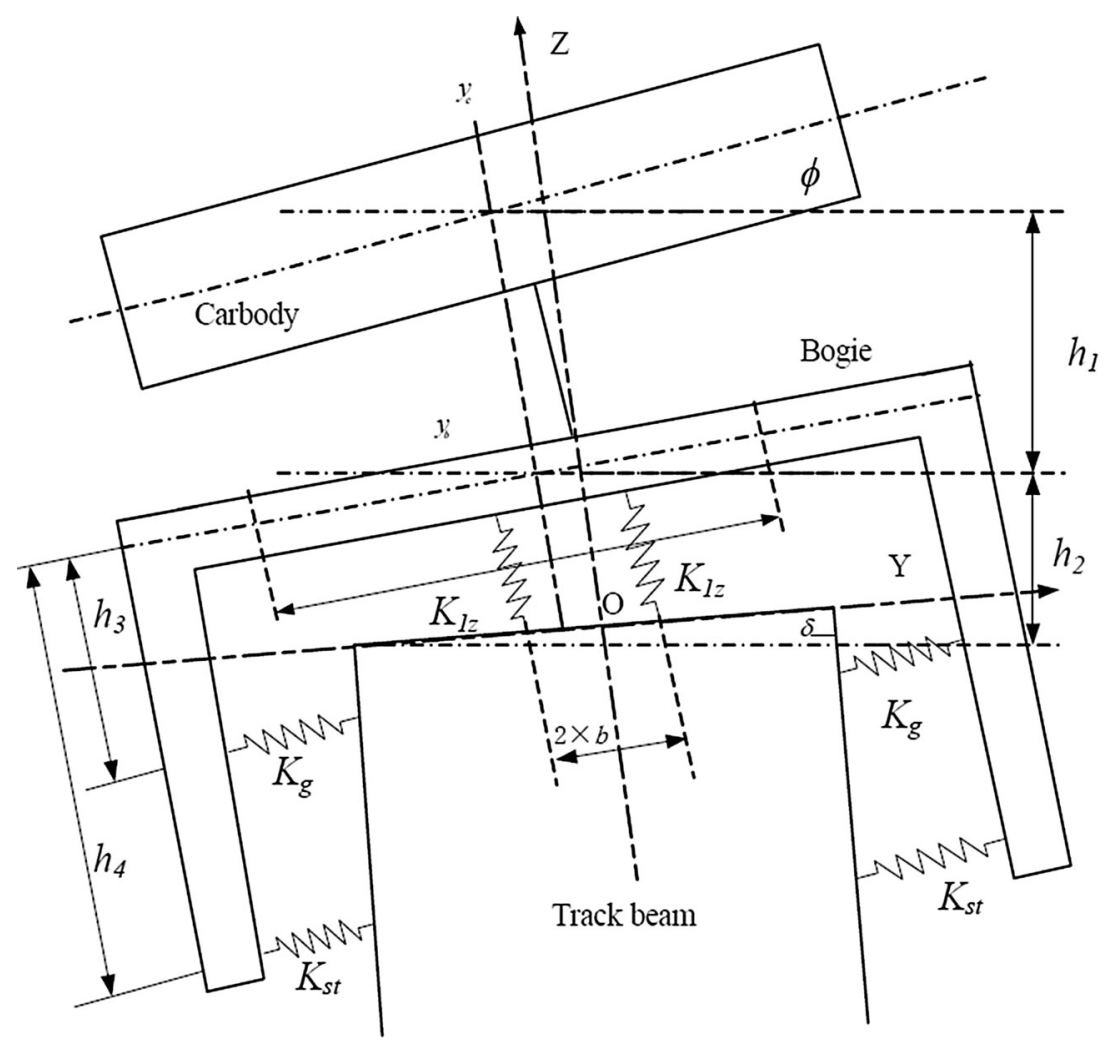

\section{Conclusion}

In this study, a new type of straddle-type monorail vehicle single-axle bogie is developed. The vertical suspension system uses tumbler structure. One end of the tumbler is fixed to the framework bottom via rotational joints, while the other end supports the framework via air springs. The lateral suspension system uses suspenders. Lateral elasticity was provided by the lateral oscillation of the suspenders. The deflection between the carbody and bogie during the motion when passing through curves is adapted by the vertical oscillation of the suspenders. The guide wheels and steady wheels rotates around the horizontal axle at the end of the framework. Rubber springs are set between the spindles and framework, and make it easier to 
adjust the pre-compressive pressure between the steady wheels and guide wheels.

The multi-body dynamics UM software is utilized to construct the single-vehicle dynamic model. Via simulation, its dynamic performance was analyzed. Dynamic analysis results indicated that the straddle-type monorail vehicle designed in this study has a favorable curve passing-through motion performance. When the A-level road spectrum coefficient is 0.5 , the stability index of the monorail vehicle is excellent within the speed range of $90 \mathrm{~km} / \mathrm{h}$.

The calculation formula of the flexibility coefficient of this new monorail vehicle was deduced, with related flexibility coefficients obtained. When all the guide wheels are in contact with steady wheels at the same time, the flexibility coefficient is 0.284 . When steady wheels on one side and guide wheels on the opposite side leave the track surface, the flexibility coefficient is 0.651 .

Open Access This article is distributed under the terms of the Creative Commons Attribution 4.0 International License (http:// creativecommons.org/licenses/by/4.0/), which permits unrestricted use, distribution, and reproduction in any medium, provided you give appropriate credit to the original author(s) and the source, provide a link to the Creative Commons license, and indicate if changes were made.

\section{References}

1. Liu Y (2007) Development model of monorail transit system. Chin Railw 6:69-71

2. Jun X (2013) Analysis on the adaptability of monorail transit. Electr Locomot Mass Transit Veh 4:20-23

3. Liu S (2003) Development of the straddle type single-rail bogies in Chongqing. Roll Stock 9:18-21

4. Xia Z (2016) Improvement and innovation of bombardier monorail technology. Mod Urban Transit 2:97-100

5. Ren L, Zhou J, Shen G (2004) Dynamics model and simulation study of a straddle type monorail car. China Railw Sci 4:26-31

6. Du Z, Li N, Chen S (2012) Simulation of the curve negotiation performance of straddle-type monorail vehicle. Urban Mass Transit 7:22-25

7. Ren L, Ji Y Critical rolling angle of straddle-type monorail vehicle. J Tongji Univ (Natural Science Edition) 